BMJ Open Diabetes

Research \& Care

\title{
Long-term changes in carbohydrate tolerance, insulin secretion and action in African-American patients with obesity and history of hyperglycemic crises
}

\author{
Priyathama Vellanki (D) , ${ }^{1}$ Darko Stefanovski, ${ }^{2}$ Isabel I Anzola, ${ }^{1}$ Dawn D Smiley, ${ }^{1}$ \\ Limin Peng, ${ }^{3}$ Guillermo E Umpierrez (D) ${ }^{1}$
}

To cite: Vellanki $P$,

Stefanovski D, Anzola II, et al. Long-term changes in carbohydrate tolerance, insulin secretion and action in AfricanAmerican patients with obesity and history of hyperglycemic crises. BMJ Open Diab Res Care 2020;8:e001062. doi:10.1136/

bmjdrc-2019-001062

PV and DS contributed equally.

Received 20 November 2019 Revised 31 March 2020 Accepted 1 May 2020

Check for updates

(c) Author(s) (or their employer(s)) 2020. Re-use permitted under CC BY-NC. No commercial re-use. See rights and permissions. Published by BMJ.

${ }^{1}$ Department of Medicine, Division of Endocrinology, Metabolism and Lipids, Emory University School of Medicine, Atlanta, Georgia, USA

${ }^{2}$ Department of Clinical Studies-New Bolton Center, University of Pennsylvania School of Veterinary Medicine, Philadelphia, Pennsylvania, USA ${ }^{3}$ Department of Biostatistics and Bioinformatics, Rollins School of Public Health, Emory University, Atlanta, Georgia, USA

Correspondence to Dr Priyathama Vellanki; priyathama.vellanki@emory. edu

\section{ABSTRACT}

Introduction Many African-Americans (AA) with obesity with newly diagnosed diabetes presenting with diabetic ketoacidosis (DKA) or severe hyperglycemia (SH) discontinue insulin therapy and achieve nearnormoglycemia remission (hemoglobin A1c (HbA1c) $<7 \%$, fasting blood glucose (FBG) $<130 \mathrm{mg} / \mathrm{dL}$ ) and able to be managed on oral antidiabetic agents $(O A D)$ during follow-up. Using combined data from two randomized controlled trials, we assessed long-term carbohydrate tolerance and changes in insulin sensitivity and insulin secretion.

Research design and methods Seventy-five participants with DKA ( $n=33)$ and SH $(n=42)$ underwent 2-hour $75 \mathrm{~g}$ oral glucose tolerance test (OGTT) after insulin discontinuation and every 6 months until hyperglycemia relapse (FBG $\geq 130 \mathrm{mg} / \mathrm{dL}, \mathrm{HbA} 1 \mathrm{c}>7 \%$ or two random $\mathrm{BG}$ $\geq 180 \mathrm{mg} / \mathrm{dL}$ ) while treated with OAD (metformin, sitagliptin or pioglitazone) or placebo. Glucose tolerance status was defined as per the American Diabetes Association. Sensitivity index $\left(\mathrm{S}_{i}\right)$ was calculated by oral minimal model, insulin secretion as the incremental area under the curve of insulin (IncreAUC) and disposition index (DI) as S. $x$ IncreAUC.

Results During remission, OGTT showed normal glucose tolerance (NGT) $(n=9(12 \%))$, prediabetes $(n=34$ $(45 \%))$ and diabetes $(n=32(43 \%))$. DI and S. were higher in patients with NGT versus prediabetes versus

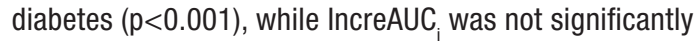
different among NGT, prediabetes and diabetes $(p=0.14)$. Achieving NGT status did not prolong nearnormoglycemia remission. OAD treatment significantly prolonged hyperglycemia relapse-free survival (log-rank $\mathrm{p}=0.0012$ ) compared with placebo and was associated with lower hyperglycemia relapse (HR: $0.45,95 \% \mathrm{Cl}$ : (0.21 to 0.96), $p=0.04$ ).

Conclusions In AA patients with obesity with history of DKA and SH, near-normoglycemia remission is associated with improved insulin secretion and action with half of patients achieving NGT or prediabetes, and only half having diabetes on OGTT. NGT and prediabetes on OGTT were not associated with prolonged hyperglycemia relapse-free survival.

Trial registration number NCT01099618, NCT00426413.

\section{Significance of this study}

What is already known about this subject?

- Approximately $50 \%$ of African-Americans who present with new-onset diabetic ketoacidosis (DKA) or severe hyperglycemia at new onset of diabetes achieve near-normoglycemia remission after intensive insulin treatment

- The period of near-normoglycemia remission is variable with some patients needing oral antidiabetic agents while some patients do not require any oral antidiabetic agents.

What are the new findings?

- The patients who achieve near-normoglycemia remission have a heterogeneous phenotype.

- Despite presenting with DKA or severe hyperglycemia, oral glucose tolerance testing (OGTT) at near-normoglycemia remission shows that $\sim 50 \%$ of patients do not have diabetes while $12 \%$ have a normal OGTT.

- Normal glucose tolerance is characterized by higher insulin sensitivity compared with prediabetes or diabetes at remission.

- Initiation of oral antidiabetic agents is important to sustain near-normoglycemia remission.

How might these results change the focus of research or clinical practice?

- Further studies need to be performed regarding the long-term treatment of patient who have normal glucose tolerance.

\section{INTRODUCTION}

More than half of newly diagnosed AfricanAmericans with obesity presenting with unprovoked diabetic ketoacidosis (DKA) exhibit clinical, metabolic, immune and genetic features of type 2 diabetes during follow-up. ${ }^{1-6}$ At presentation, these patients have severe pancreatic beta $(\beta)$-cell dysfunction and increased insulin resistance. 
Furthermore, our group and other have shown that African-American patients with obesity who present with severe hyperglycemia without ketoacidosis have similar impaired $\beta$-cell dysfunction and insulin resistance. ${ }^{378}$ In $\sim 70 \%$ of patients, aggressive management with insulin in patients with obesity presenting with DKA and severe hyperglycemia results in significant improvement in pancreatic $\beta$-cell function and insulin sensitivity, sufficient to allow discontinuation of insulin and maintain near-normoglycemia remission for several months to years with lifestyle modification alone or with oral antidiabetic agents (OAD). ${ }^{357910}$

The duration of near-normoglycemia remission is variable. We performed two studies that showed that initiation of metformin, sitagliptin or pioglitazone after insulin discontinuation prolongs remission. In addition, the patients who achieve remission represent a heterogeneous population. In a study by Banerji $e t a l{ }^{7}$ oral glucose tolerance test (OGTT) performed at time of nearnormoglycemia remission showed that $16.7 \%$ of patients achieved normalization of the OGTT while $33.3 \%$ had impaired glucose tolerance and 50\% remained with diabetes. In the Diabetes Prevention Program (DPP), people who achieved normalization of the OGTT at least once during the study period showed a $56 \%$ lower incidence of diabetes compared with people who stayed with prediabetes irrespective of being randomized to physical activity, placebo or metformin. ${ }^{11}$ In the DPP study, normalization of the OGTT was associated with higher insulin sensitivity and secretion. In this study, we aimed to examine the differences in insulin secretion and action based on OGTT status at near-normoglycemia remission and whether OGTT status influenced long-term hyperglycemia relapse-free survival independent of OAD use. Since each study had a small number of participants with a normalized OGTT, inclusion/exclusion criteria were similar in both studies and performed at the same center, we combined the OGTT results from both studies to assess the effect of OGTT status on hyperglycemia relapse-free survival.

\section{RESEARCH DESIGN AND METHODS \\ Study participants}

This study was a post hoc analysis of data from two randomized controlled studies conducted at Grady Memorial Hospital in Atlanta, Georgia, USA. ${ }^{12}$

Briefly, participants were of African-American ancestry, aged 18-65 years, overweight or obese (body mass index $(\mathrm{BMI})>28 \mathrm{~kg} / \mathrm{m}^{2}$ ), presenting with unprovoked DKA or severe hyperglycemia at diagnosis of diabetes. ${ }^{12}$ Participants with contraindications to any of the medications used in the individual randomized controlled studies (metformin, sitagliptin or pioglitazone), history of pancreatitis, moderate or severe heart failure, significant anemia, pregnant or unable to consent were excluded. DKA was defined as blood glucose (BG) $\geq 250 \mathrm{mg}$ / dL $\quad(13.9 \mathrm{mmol} / \mathrm{L}), \quad \mathrm{pH}<7.30$, bicarbonate levels
$<18 \mathrm{mmol} / \mathrm{L}$ and positive ketonemia defined as betahydroxybutyrate $>3 \mathrm{mmol} / \mathrm{L} .{ }^{13}$ Severe hyperglycemia was defined as $\mathrm{BG}>400 \mathrm{mg} / \mathrm{dL}(22.2 \mathrm{mmol} / \mathrm{L})$, $\mathrm{pH}>7.30$, $\mathrm{HCO} 3 \geq 18 \mathrm{mmol} / \mathrm{L}$ and without ketonemia.

\section{Study protocol}

After acute resolution of DKA/hyperglycemia, all participants were treated intensively with subcutaneous insulin to a target fasting BG (FBG) and premeal BG between 70 and $130 \mathrm{mg} / \mathrm{dL}(3.9-7.2 \mathrm{mmol} / \mathrm{L})$. Insulin was decreased up to 12 weeks until near-normoglycemia remission was achieved. Near-normoglycemia remission was defined as $\mathrm{FBG}<130 \mathrm{mg} / \mathrm{dL}(7.2 \mathrm{mmol} / \mathrm{L})$ and random BG $<180 \mathrm{mg} / \mathrm{dL}(10 \mathrm{mmol} / \mathrm{L})$, at least a week off insulin therapy and with a hemoglobin A1c (HbAlc) $<7 \%$ (53 mmol/L). HbA1c and BG levels were checked a week after insulin discontinuation. After discontinuing insulin, participants were randomized to an oral antidiabetic agent $(\mathrm{OAD})$ or placebo. In one study, participants were randomized to three groups: sitagliptin $100 \mathrm{mg}$ daily, metformin $1000 \mathrm{mg}$ daily or placebo. ${ }^{12}$ In the second study, participants were randomized to two groups: pioglitazone $30 \mathrm{mg}$ daily or placebo. Prior to randomization, all participants received a $75 \mathrm{~g}$ OGTT. After randomization (month 0 ), study participants were followed at the Grady Diabetes Clinic every 4 weeks until 3 months and then every 3 months until 27 months or until they had a hyperglycemic relapse while on oral medication.

All randomized participants underwent OGTTs at randomization ( 0 months), 3, 9, 15, 21 and 27 months or until hyperglycemia relapse (defined as an FBG $>130 \mathrm{mg}$ / $\mathrm{dL}(7.2 \mathrm{mmol} / \mathrm{L})$, random blood glucose $>180 \mathrm{mg} / \mathrm{dL}$ $(10 \mathrm{mmol} / \mathrm{L})$ for two consecutive days or $\mathrm{HbAlc} \geq 7 \%$ (53 $\mathrm{mmol} / \mathrm{L}))$.

\section{Medications}

Sitagliptin was provided by Merck \& Co and pioglitazone by Takeda Pharmaceuticals. Metformin was purchased from the research pharmacy at Grady Memorial Hospital. The pharmaceutical companies were not involved in study design, subject recruitment, data analyses or writing of the manuscript.

\section{Modified oral glucose tolerance test}

After an 8-10hours overnight fast, a $75 \mathrm{~g}$ OGTT was performed in participants between 08:00 and 10:00 hours. Glucose and insulin levels were checked at 0,15 , $30,60,90$ and $120 \mathrm{~min}$.

\section{Measured outcomes and calculations}

Glucose levels from the OGTT at month 0 was used to define the different glucose tolerance groups as recommended by the American Diabetes Association. ${ }^{14}$ Normal glucose tolerance was defined as FBG $<100 \mathrm{mg} / \mathrm{dL}$ $(5.6 \mathrm{mmol} / \mathrm{L})$ and 2 -hour BG $<140 \mathrm{mg} / \mathrm{dL}(7.8 \mathrm{mmol} / \mathrm{L})$. Prediabetes was defined as FBG between 100 and $125 \mathrm{mg}$ / $\mathrm{dL}(5.5-6.9 \mathrm{mmol} / \mathrm{L})$ or 2-hour BG between 140 and $199 \mathrm{mg} / \mathrm{dL}(7.8-11.1 \mathrm{mmol} / \mathrm{L})$. Diabetes was defined as 
Table 1 Baseline characteristics of patients presenting with hyperglycemic crises at near-normoglycemia remission according to OGTT

\begin{tabular}{|c|c|c|c|c|}
\hline & $\begin{array}{l}\text { NGT } \\
(n=9)\end{array}$ & $\begin{array}{l}\text { Prediabetes } \\
(n=34)\end{array}$ & $\begin{array}{l}\text { Diabetes } \\
(\mathrm{n}=32)\end{array}$ & $P$ value \\
\hline Age, years & $45 \pm 13$ & $45 \pm 10$ & $49 \pm 10$ & 0.45 \\
\hline $\mathrm{BMI}, \mathrm{kg} / \mathrm{m}^{2}$ & $39.6 \pm 16.8$ & $34.9 \pm 10.3$ & $36.6 \pm 8.8$ & 0.76 \\
\hline Sex, n (\%) & & & & 0.22 \\
\hline Female & $1(11)$ & $15(44)$ & $12(37.5)$ & \\
\hline Male & $8(89)$ & $19(56)$ & $20(62.5)$ & \\
\hline Diagnosis, n (\%) & & & & 0.95 \\
\hline DKA & $4(44)$ & $14(41)$ & $15(47)$ & \\
\hline Severe hyperglycemia & $5(56)$ & $20(59)$ & $17(53)$ & \\
\hline $\mathrm{HbA} 1 \mathrm{c}, \%$ & $13.0 \pm 1.8$ & $12.7 \pm 2.2$ & $13.0 \pm 2.4$ & 0.82 \\
\hline Family history of type 2 diabetes, $n(\%)$ & $6(67)$ & $30(88)$ & $27(84)$ & $>0.99$ \\
\hline Insulin dose, units $/ \mathrm{kg} /$ day & $0.46 \pm 0.17$ & $0.57 \pm 0.21$ & $0.67 \pm 0.30$ & 0.13 \\
\hline Duration of insulin treatment (weeks) & & & & $>0.99$ \\
\hline$\leq 8$ & $3(33)$ & $13(38)$ & $13(41)$ & \\
\hline$>8$ & $6(67)$ & $21(62)$ & $19(59)$ & \\
\hline OAD, n (\%) & $7(78)$ & 27 (82) & $16(50)$ & 0.07 \\
\hline Metformin & $2(22)$ & $7(21)$ & 7 (22) & \\
\hline Sitagliptin & $1(11)$ & $10(30)$ & $5(16)$ & \\
\hline Pioglitazone & $4(44)$ & $10(30)$ & $4(13)$ & \\
\hline Placebo & $2(22)$ & $6(18)$ & $16(50)$ & \\
\hline
\end{tabular}

Data are expressed as mean \pm SD unless otherwise noted. OAD, NGT (fasting glucose $<100 \mathrm{mg} / \mathrm{dL}$ and 2-hour glucose $<140 \mathrm{mg} / \mathrm{dL}$ ), prediabetes (fasting glucose 100-125 mg/dL or 2-hour glucose $140-199 \mathrm{mg} / \mathrm{dL}$ ), diabetes (fasting glucose $\geq 126 \mathrm{mg} / \mathrm{dL}$ or 2-hour glucose $\geq 200 \mathrm{mg} / \mathrm{dL}$ ).

BMI, body mass index; DKA, diabetic ketoacidosis; HbA1c, hemoglobin A1c; NGT, normal fasting glucose/normal glucose tolerance; OAD, oral antidiabetic agent; OGTT, oral glucose tolerance test.

FBG $\geq 126 \mathrm{mg} / \mathrm{dL}(7.0 \mathrm{mmol} / \mathrm{L})$ or 2 -hour BG $\geq 200 \mathrm{mg} /$ $\mathrm{dL}(11.1 \mathrm{mmol} / \mathrm{L})$.

Insulin sensitivity $\left(\mathrm{S}_{\mathrm{i}}\right)$ and $\beta$-cell function were calculated using OGTT-derived measures. We had previously validated our 120 min 6-point oral minimal model $\mathrm{S}$, which was similar to the 120 min 7 -point minimal model. ${ }^{12}$ Therefore, we calculated $\mathrm{S}_{\mathrm{i}}$ using glucose and insulin levels from the 6-point OGTT using the oral minimal model. Incremental area under the curve of insulin levels (IncreAUC $\mathrm{C}_{\mathrm{i}}$ ) using the trapezoidal method was used to calculate insulin secretion. ${ }^{15}$ Disposition index was calculated as the product of $\mathrm{S}_{\mathrm{i}}$ and IncreAUC $\mathrm{C}_{\mathrm{i}}$.

\section{Analytic techniques}

Assays for glucose and insulin were performed at the Endocrinology/Lipoprotein Laboratory at the University of Tennessee Health Sciences Center. ${ }^{16}$ HbAlc and GAD-65 antibody tests were measured at the central laboratory at Grady Memorial Hospital.

\section{Statistical analyses}

The main outcome was to assess differences among the different OGTT categories in disposition index, $\mathrm{S}_{\mathrm{i}}$ and IncreAUC. Since both studies had similar inclusion/ exclusion criteria and conducted at the same site, data were combined for both studies. In each of the individual randomized studies, there were no differences between the DKA and severe hyperglycemia groups in hyperglycemia relapse-free survival. Therefore, the DKA and severe hyperglycemia groups were also combined for this analysis. The metformin, sitagliptin and pioglitazone groups had small numbers, therefore all three medication groups were combined. Hyperglycemia relapse-free survival was compared between the different glucose tolerance groups using Kaplan-Meier curves and logrank tests. We performed univariate and multivariate Cox proportional hazards analysis to evaluate the associations between multiple factors and hyperglycemia relapse-free remission. Continuous variables were compared using Kruskal-Wallis tests for three group comparisons and Wilcoxon rank-sum tests for two group comparisons. Continuous variables are expressed as mean \pm SD. Discrete variables were compared using $\chi^{2}$ tests and expressed as per cent. All analyses were performed using SAS V.9.4 (Cary, North Carolina, USA).

\section{RESULTS}

Seventy-five participants with DKA or severe hyperglycemia underwent an OGTT after near-normoglycemia 
Table 2 Baseline characteristics of patients presenting with hyperglycemic crises at near-normoglycemia remission according to randomized groups

\begin{tabular}{|c|c|c|c|}
\hline & $\begin{array}{l}\text { OAD } \\
(n=50)\end{array}$ & $\begin{array}{l}\text { Placebo } \\
(n=24)\end{array}$ & $P$ value \\
\hline Age, years & $47 \pm 10$ & $47 \pm 11$ & 0.89 \\
\hline $\mathrm{BMI}, \mathrm{kg} / \mathrm{m}^{2}$ & $36.4 \pm 10.4$ & $35.9 \pm 7.1$ & 0.82 \\
\hline Sex, n (\%) & & & $>0.99$ \\
\hline Female & $18(36)$ & $9(37.5)$ & \\
\hline Male & $32(64)$ & $15(62.5)$ & \\
\hline Diagnosis, n (\%) & & & 0.044 \\
\hline DKA & $26(52)$ & $6(25)$ & \\
\hline Severe hyperglycemia & $24(48)$ & $18(75)$ & \\
\hline $\mathrm{HbA1c}, \%$ & $13.1 \pm 2.0$ & $12.5 \pm 2.6$ & 0.30 \\
\hline $\begin{array}{l}\text { Family history of type } 2 \\
\text { diabetes, n (\%) }\end{array}$ & $42(84)$ & $20(83)$ & $>0.99$ \\
\hline $\begin{array}{l}\text { Insulin dose, } \\
\text { units/kg/day }\end{array}$ & $0.56 \pm 0.23$ & $0.69 \pm 0.29$ & 0.12 \\
\hline \multicolumn{2}{|c|}{ Duration of insulin treatment (weeks) } & & 0.19 \\
\hline$\leq 8$ & $22(44)$ & 7 (29) & \\
\hline$>8$ & $28(56)$ & $16(67)$ & \\
\hline OGTT status, n (\%) & & & 0.020 \\
\hline NGT & $7(14)$ & $2(8.3)$ & \\
\hline Prediabetes & $27(54)$ & $6(25)$ & \\
\hline Diabetes & $16(32)$ & $16(67)$ & \\
\hline OAD type, n (\%) & & & N/A \\
\hline Metformin & $16(32)$ & $\mathrm{N} / \mathrm{A}$ & \\
\hline Sitagliptin & $16(32)$ & $\mathrm{N} / \mathrm{A}$ & \\
\hline Pioglitazone & $18(36)$ & $\mathrm{N} / \mathrm{A}$ & \\
\hline
\end{tabular}

Data are expressed as mean $\pm S D$ unless otherwise noted. OAD, NGT (fasting glucose $<100 \mathrm{mg} / \mathrm{dL}$ and 2-hour glucose $<140 \mathrm{mg}$ / $\mathrm{dL}$ ), prediabetes (fasting glucose 100-125 mg/dL or 2-hour glucose $140-199 \mathrm{mg} / \mathrm{dL}$ ), diabetes (fasting glucose $\geq 126 \mathrm{mg} / \mathrm{dL}$ or 2-hour glucose $\geq 200 \mathrm{mg} / \mathrm{dL}$ ).

$\mathrm{BMI}$, body mass index; DKA, diabetic ketoacidosis; HbA1c, hemoglobin A1c; N/A, not available; NGT, normal fasting glucose/ normal glucose tolerance; OAD, oral antidiabetic agent; OGTT, oral glucose tolerance test.

remission within 1 week after stopping insulin therapy. Of them, $12 \%(\mathrm{n}=9)$ had normal glucose tolerance, $45 \%$ $(n=34)$ with prediabetes and $43 \%(n=32)$ with diabetes. There were no differences in baseline demographics between the normal glucose tolerance, prediabetes and diabetes groups (table 1). Even though not statistically significant, a higher percentage of participants with normal glucose tolerance and prediabetes were randomized to the OAD compared with the placebo group (table 1). Treatment allocation to OAD and placebo is shown in table 2. There was one participant who received an OGTT at remission but did not get randomized to an OAD. Therefore, 50 participants were randomized to $\mathrm{OAD}$ and 24 were randomized to placebo after near-normoglycemia remission (table 2). Of these, $32 \%$
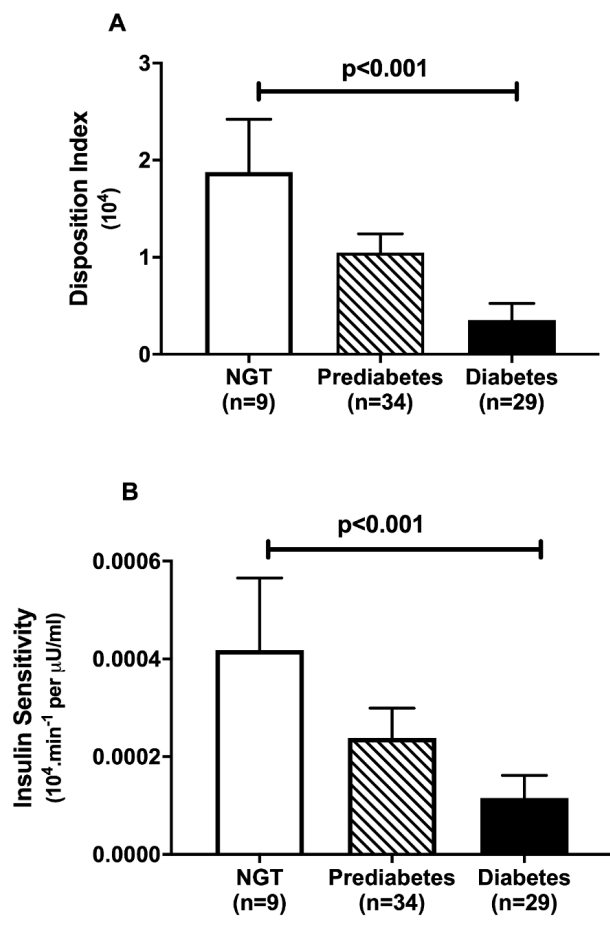

C

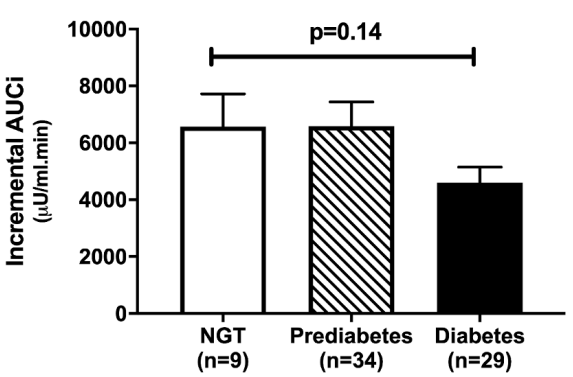

Figure 1 Disposition index is significantly higher in patients who attained NGT (clear bars) compared with prediabetes (hatched bars) and diabetes (black bars) (A). The difference in disposition index was explained by increased insulin sensitivity (B) rather than insulin secretion (C). Data are shown as mean \pm SEM. NGT, prediabetes and diabetes are defined as per the American Diabetes Association. incrementalAUCi, incremental area under the curve of insulin; NGT, normal glucose tolerance.

received metformin and sitagliptin while $36 \%$ received pioglitazone. There were no differences in the age, BMI, family history of type 2 diabetes, hemoglobin Alc or insulin doses (table 2). There were significantly more participants with severe hyperglycemia in the placebo group compared with the OAD group (table 2).

In the participants who had normal glucose tolerance at remission, disposition index was significantly higher than in participants who had prediabetes and diabetes, $\mathrm{p}<0.001$ (figure 1A). This difference in disposition index was due to differences in insulin sensitivity $\left(\mathrm{S}_{\mathrm{i}}\right)$ rather than insulin secretion (IncreAUC $\left.C_{i}\right)$. Participants with normal glucose tolerance had higher $\mathrm{S}_{\mathrm{i}}$ compared with prediabetes or diabetes group, $\mathrm{p}<0.001$ (figure 1B), while IncreAUC $_{\mathrm{i}}$ did not differ (figure 1C). Disposition index, 


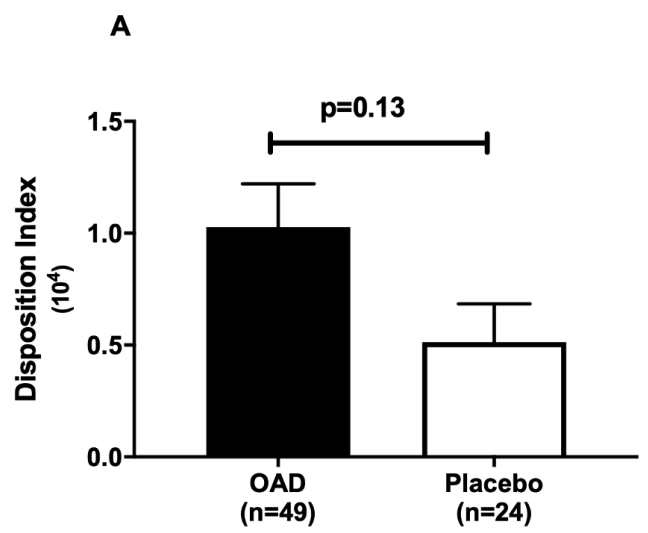

B

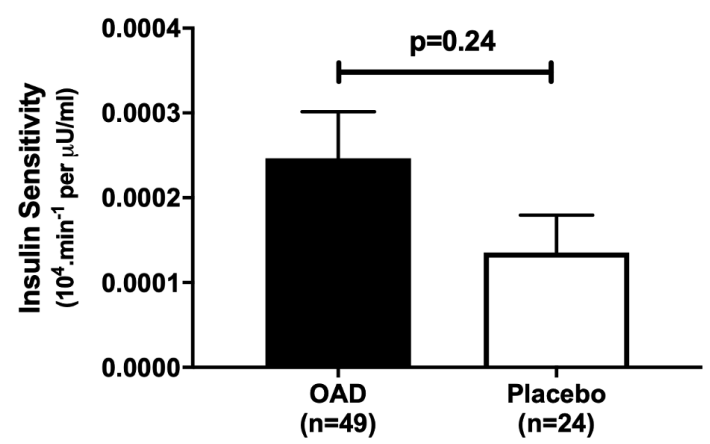

C

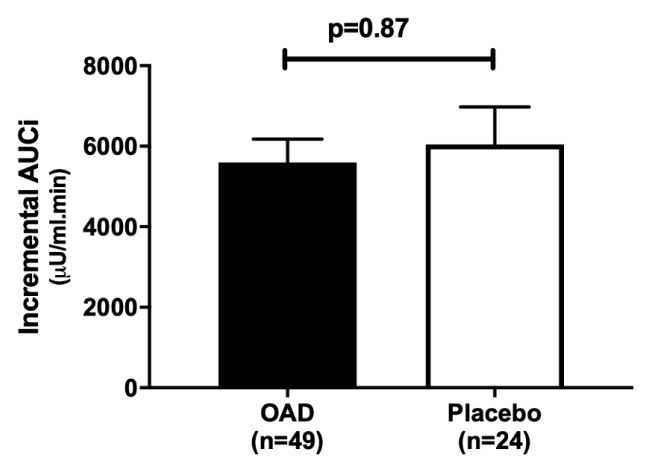

Figure 2 Disposition index (A), insulin sensitivity (B) and incremental area under the curve $(C)$ did not differ at time of remission in patients randomized to oral antidiabetic agents (black bars) compared with placebo (clear bars). Data are shown as mean \pm SEM. incrementalAUCi, incremental area under the curve of insulin; OAD, oral antidiabetic agents.

$\mathrm{S}_{\mathrm{i}}$ and Incre $\mathrm{AUC}_{\mathrm{i}}$ calculated from OGTT at remission did not differ significantly in participants who were randomized to OAD compared with placebo (figure 2).

The median time to hyperglycemia relapse or end of follow-up was 392 days. Hyperglycemia relapse-free survival did not differ significantly according to the OGTT groups (figure 3); however, initiation of an OAD was associated with significantly increased hyperglycemia relapse-free survival (log-rank $\mathrm{p}=0.0012$ ) (figure 4$)$. There were no significant differences in prolongation of nearnormoglycemia remission among participants receiving metformin, pioglitazone or sitagliptin. Univariate analysis

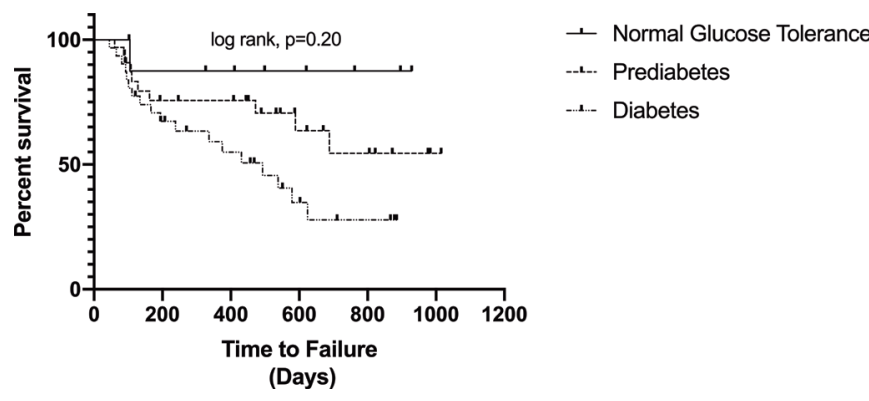

Figure 3 Survival curve of hyperglycemia relapse-free survival after near-normoglycemia remission according to oral glucose tolerance test status. Hyperglycemia relapsefree survival did not differ among patients with normal glucose tolerance, prediabetes and diabetes (log-rank $p=0.20$ ).

showed that receiving an OAD was associated with lower risk of hyperglycemia relapse compared with receiving placebo (HR 0.33, 95\% CI (0.16 to 0.67), p=0.002). Presentation with DKA was also associated with lower risk of hyperglycemia relapse compared with participants presenting with severe hyperglycemia (HR 0.39, 95\% CI $(0.17$ to 0.87$), p=0.02)$. In a multivariable Cox hazards model, after adjustment for OGTT status, initiation of OAD was still significantly associated with lower risk of hyperglycemia relapse (HR $0.37,95 \%$ CI (0.18 to 0.77$)$, $\mathrm{p}=0.008$ ). In a multivariate model which adjusts for age, OAD use and the presentation with DKA versus severe hyperglycemia, OAD use was associated with lower risk of hyperglycemia relapse (HR $0.45,95 \%$ CI (0.21 to 0.96$)$, $\mathrm{p}=0.04$ ) while presentation with DKA or severe hyperglycemia did not remain significant $(\mathrm{p}=0.07)$.

\section{DISCUSSION}

Our study shows that African-American patients with obesity presenting with DKA and severe hyperglycemia who achieve near-normoglycemia represent a heterogeneous group. Despite presenting with DKA and/or severe hyperglycemia, $57 \%$ participants achieved a normal

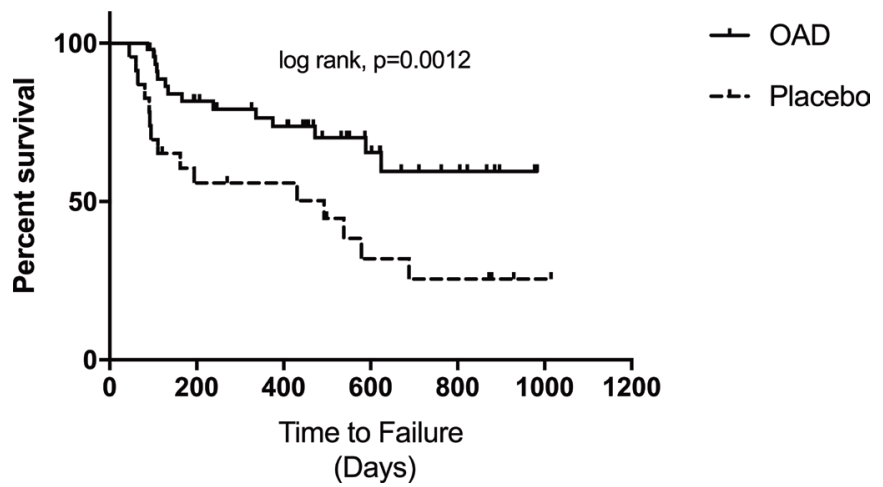

Figure 4 Survival curve of hyperglycemia relapse-free survival after remission in patients with diabetic ketoacidosis and severe hyperglycemia. Hyperglycemia relapse-free survival in patients randomized to oral antidiabetic agents (OAD) was longer compared with patients randomized to placebo, log-rank $p=0.0012$. 
glucose tolerance or prediabetes at near-normoglycemia remission, with only $43 \%$ of participants having diabetes on OGTT. Normalization of the OGTT was associated with higher disposition index than prediabetes or diabetes, however, there was no association with duration of hyperglycemia relapse-free survival.

Our results are in agreement with the report by Banerji et $a l^{7}{ }^{7}$ who reported in black participants with obesity presenting with DKA and severe hyperglycemia, $17 \%$ had normalized OGTT and with a third of the participants with impaired glucose tolerance and another half of the participants with diabetes. In that study, attaining normal glucose tolerance status did not predict long-term relapse-free survival. Presentation with lower glucose level and female sex led to longer hyperglycemia relapsefree survival over an 8-year period.

We found that normalization of OGTT was characterized by higher insulin sensitivity rather than secretion compared with prediabetes and diabetes at nearnormoglycemia remission. These data differ from the DPP where participants with prediabetes who were able to normalize their glucose tolerance had higher insulin sensitivity and secretion. ${ }^{11}$ Data from Banerji et $a l^{7}$ were similar to our study indicating no differences in insulin secretion among the three groups, but insulin sensitivity was significantly higher in the participants who attained a normal OGTT. Similar to our study, insulin secretion was determined by AUC with insulin levels from the OGTT time points. We likely did not see a difference in insulin secretion due to defects in insulin clearance in our participants with prediabetes and diabetes. Insulin clearance is directly correlated with insulin sensitivity ${ }^{17}$ and insulin clearance is decreased in insulin-resistant individuals with obesity. ${ }^{18}$ It is possible that insulin clearance is impaired in the more insulin-resistant participants who remained with prediabetes and diabetes leading to lack of differences in our measures of insulin secretion.

We investigated the effect of antidiabetic therapy on hyperglycemia remission after insulin discontinuation. Initiation of an $\mathrm{OAD}$ resulted in prolonged remission in our cohort. More importantly, initiation of OAD was the only predictor for sustaining near-normoglycemia remission independent of having normalization of the OGTT, prediabetes or diabetes on OGTT. The effect of initiation of an $\mathrm{OAD}$ was significant even when adjusted for presentation with DKA or severe hyperglycemia. This is consistent with published studies from our group and others where initiation of an oral agent prolonged remission after discontinuation of insulin therapy in patients with a history of DKA or severe hyperglycemia. ${ }^{10} 19$

There are several limitations to our study. Since this is a post hoc analysis of two randomized controlled studies and participants were already started on an $\mathrm{OAD}$, we were not able to assess the natural course of glucose control based on the different OGTT groups at remission. Metformin, sitagliptin and pioglitazone have differing mechanisms of actions, which could have affected hyperglycemia relapse. However, we did not have adequate numbers to discern the differences in insulin sensitivity and secretion in response to metformin, sitagliptin or pioglitazone. Since one study had two and the other study had three randomization groups, when data were combined, the study was biased toward more participants randomized to the placebo group. We also did not have sample to measure C-peptide levels to calculate insulin clearance. Nevertheless, this study shows important metabolic differences in patients who undergo remission and emphasized the importance of starting OAD after remission from insulin.

\section{CONCLUSIONS}

In summary, we showed that African-Americans with obesity who present with DKA and severe hyperglycemia with near-normoglycemia remission represent a heterogeneous group of patients. Despite presenting with DKA and severe hyperglycemia, more than half of patients have normal glucose tolerance or prediabetes, with less than half having diabetes on OGTT at the time of insulin remission. Normalization of OGTT was characterized by higher insulin sensitivity rather than insulin secretion. Although initiation of an $\mathrm{OAD}$ was the significant predictor of long-term near-normoglycemia remission, more studies are needed to explore the underlying pathophysiology of patients achieving a normal glucose tolerance. Future studies with larger number of patients are needed to characterize metabolic parameters along with the natural clinical course in African-Americans with obesity presenting with hyperglycemic crises.

Contributors PV conceived the study, wrote the first draft and edited the manuscript. DS performed the minimal model analysis. DDS and IIA conducted the study. LP performed data analysis. GEU conceived and performed the study. All authors critically edited the manuscript. PV is the guarantor of the work.

Funding PV is supported in part by K12HD085850 and K23DK113241-01A1. This work was funded by K08DK0830361 (DDS) and was supported by the National Center for Advancing Translational Sciences Award number (UL1TR002378) and 1P30DK111024-01 from the National Institutes of Health and National Research Resources. GEU is partly supported by research grants from the NIH/NATS UL1 TR002378 from the Clinical and Translational Science Award program, and 1P30DK111024-01 from NIH and National Center for Research Resources.

Competing interests PV has received consulting fees from Boehringer-Ingelheim and Merck. GEU has received unrestricted research support for inpatient studies (to Emory University) from Novo Nordisk, Dexcom and Sanofi. DDS has received fees for serving on the Speaker Bureau for Novo Nordisk, Merck and Sanofi. The other authors do not have any significant conflicts of interest.

Patient consent for publication Not required.

Ethics approval The Institutional Review Board at Emory University approved to report the combined results of the two randomized controlled studies (NCT01099618 and NCT00426413, www.Clinicaltrials.gov).

Provenance and peer review Not commissioned; externally peer reviewed

Data availability statement Data are available on reasonable request from the PI. Please email at pvellan@emory.edu for any requests or questions.

Open access This is an open access article distributed in accordance with the Creative Commons Attribution Non Commercial (CC BY-NC 4.0) license, which permits others to distribute, remix, adapt, build upon this work non-commercially, and license their derivative works on different terms, provided the original work is properly cited, appropriate credit is given, any changes made indicated, and the use is non-commercial. See: http://creativecommons.org/licenses/by-nc/4.0/. 
ORCID iDs

Priyathama Vellanki http://orcid.org/0000-0002-6544-015X

Guillermo E Umpierrez http://orcid.org/0000-0002-3252-5026

\section{REFERENCES}

1 Winter WE, Maclaren NK, Riley WJ, et al. Maturity-onset diabetes of youth in black Americans. N Engl J Med 1987;316:285-91.

2 Umpierrez GE, Woo W, Hagopian WA, et al. Immunogenetic analysis suggests different pathogenesis for obese and lean African-Americans with diabetic ketoacidosis. Diabetes Care 1999:22:1517-23.

3 Umpierrez GE, Casals MM, Gebhart SP, et al. Diabetic ketoacidosis in obese African-Americans. Diabetes 1995;44:790-5.

4 Umpierrez GE, Kelly JP, Navarrete JE, et al. Hyperglycemic crises in urban blacks. Arch Intern Med 1997;157:669-75.

5 Banerji MA, Chaiken RL, Huey H, et al. Gad antibody negative NIDDM in adult black subjects with diabetic ketoacidosis and increased frequency of human leukocyte antigen DR3 and DR4. Flatbush diabetes. Diabetes 1994;43:741-5.

6 Balasubramanyam A, Zern JW, Hyman DJ, et al. New profiles of diabetic ketoacidosis: type 1 vs type 2 diabetes and the effect of ethnicity. Arch Intern Med 1999;159:2317-22.

7 Banerji MA, Chaiken RL, Lebovitz HE. Long-Term normoglycemic remission in black newly diagnosed NIDDM subjects. Diabetes 1996;45:337-41.

8 McFarlane SI, Chaiken RL, Hirsch S, et al. Near-normoglycaemic remission in African-Americans with type 2 diabetes mellitus is associated with recovery of beta cell function. Diabet Med 2001;18:10-16.

9 Sobngwi E, Vexiau P, Levy V, et al. Metabolic and immunogenetic prediction of long-term insulin remission in African patients with atypical diabetes. Diabet Med 2002;19:832-5.
10 Umpierrez GE, Clark WS, Steen MT. Sulfonylurea treatment prevents recurrence of hyperglycemia in obese African-American patients with a history of hyperglycemic crises. Diabetes Care 1997;20:479-83.

11 Perreault L, Pan Q, Mather KJ, et al. Effect of regression from prediabetes to normal glucose regulation on long-term reduction in diabetes risk: results from the diabetes prevention program outcomes study. Lancet 2012;379:2243-51.

12 Vellanki P, Smiley DD, Stefanovski D, et al. Randomized controlled study of metformin and sitagliptin on long-term Normoglycemia remission in African American patients with hyperglycemic crises. Diabetes Care 2016;39:1948-55.

13 Kitabchi AE, Umpierrez GE, Miles JM, et al. Hyperglycemic crises in adult patients with diabetes. Diabetes Care 2009;32:1335-43.

14 American Diabetes Association. 2. Classification and Diagnosis of Diabetes: Standards of Medical Care in Diabetes-2018. Diabetes Care 2018;41:S13-27.

15 Tai MM. A mathematical model for the determination of total area under glucose tolerance and other metabolic curves. Diabetes Care 1994; 17:152-4

16 Stentz FB, Umpierrez GE, Cuervo R, et al. Proinflammatory cytokines, markers of cardiovascular risks, oxidative stress, and lipid peroxidation in patients with hyperglycemic crises. Diabetes 2004;53:2079-86.

17 Lorenzo C, Hanley AJG, Wagenknecht LE, et al. Relationship of insulin sensitivity, insulin secretion, and adiposity with insulin clearance in a multiethnic population: the insulin resistance atherosclerosis study. Diabetes Care 2013;36:101-3.

$18 \mathrm{Kim}$ MK, Reaven GM, Kim SH. Dissecting the relationship between obesity and hyperinsulinemia: role of insulin secretion and insulin clearance. Obesity 2017;25:378-83.

19 Banerii MA, Chaiken RL, Lebovitz HE. Prolongation of nearnormoglycemic remission in black NIDDM subjects with chronic low-dose sulfonylurea treatment. Diabetes 1995;44:466-70. 